\title{
Antiretroviral treatment attrition in Swaziland: a population-based study
}

\author{
P. G. KHUMALO ${ }^{1}$, Y. J. CHOU ${ }^{2}$ AND C. PU ${ }^{2 *}$ \\ ${ }^{1}$ Antiretroviral Treatment Unit, Mbabane Government Hospital, Mbabane, Swaziland \\ ${ }^{2}$ Institute of Public Health, National Yang-Ming University, Taipei, Taiwan \\ Received 3 March 2016; Final revision 18 July 2016; Accepted 20 July 2016; \\ first published online 22 August 2016
}

\section{SUMMARY}

Swaziland has the highest prevalence of human immunodeficiency virus (HIV) in the world. Attrition (loss to follow-up and mortality) in people living with HIV/AIDS (PLWHA) already on treatment is a major challenge, undermining achievements of the antiretroviral treatment (ART) programme in Swaziland. The contributing factors to attrition in the Swazi context are unclear. This study aims to (1) estimate attrition from the ART programme 12 months after ART initiation in Swaziland, and (2) determine the predictors of attrition in PLWHA treated with ART in Swaziland. A retrospective cohort study using national baseline data was conducted. A competing-risk Cox proportional hazard regression was used to determine the predictors of attrition. We estimated $10 \cdot 3 \%$ (95\% confidence interval $10 \cdot 1-10 \cdot 6)$ attrition in 16423 participants that initiated ART in 2012. Attrition was significantly associated with sex, age, district, treatment supporter at initiation, co-infection of HIV and TB, functional status, WHO clinical stage, and ownership of facility. Our study can form a base of policies, plans, and service delivery strategies for preventing and controlling attrition in Swaziland.

Key words: Antiretroviral treatment, attrition, HIV/AIDS, Swaziland.

\section{INTRODUCTION}

According to 2014 statistics [1], the national prevalence rate of human immunodeficiency virus (HIV) in Swaziland is the highest in the world (32\% in adults aged 18-49 years), making HIV and acquired immune deficiency syndrome (AIDS) the most serious public health concern in the country. Prevalence has peaked at $54 \%$ for women aged $30-34$ years and $47 \%$ for men aged 35-39 years [1]. Increased morbidity and mortality characterize the AIDS epidemic in Swaziland, and life expectancy has dropped from 56 years in 1995 to 49 years in 2013 [2]. The availability of antiretroviral

\footnotetext{
* Author for correspondence: Dr C. Pu, 155 Linong St. Sec 2, Beitou, Taipei, Taiwan, ROC. (Email: cypu@ym.edu.tw)
}

treatment (ART) has transformed the previously fatal HIV infection into a manageable chronic illness [3], with over $80 \%$ of people living with HIV/AIDS (PLWHA) who are eligible for treatment actually benefiting from treatment in 2012 [4]. To focus on countrywide HIV and AIDS service delivery, Swaziland established a national ART programme in 2004. At inception, one of the programme's goals was to achieve universal access to ART for eligible PLWHA. Strategies for achieving this goal have included making ART accessible free of charge, as well as expanding coverage through a three-phase process. In the first phase, ART service provision was extended from one hospital (Mbabane Government Hospital in Hhohho District) to five major hospitals distributed in all four districts of Swaziland. In the 
second phase, ART service provision was extended to five health centres and some private clinics. Finally, in the third phase, services were made available in private and public clinics [5].

The number of facilities providing ART services increased from one in 2004 to 19 in 2006, reaching 110 sites by the end of 2011. Thirty-eight of these were fully capacitated roll-out sites (i.e. they met the minimum criteria for providing ART services), constituting 18 public or mission facilities and 20 private or non-governmental organization (NGO) facilities. The remaining 72 sites were outreach sites that mainly provided drug refills for ART patients. Twenty-nine of these outreach sites also initiated patients on ART, and were supported by the public or mission hospitals and health centres. The distribution of ART service sites in the four districts of Swaziland were 20 in Hhohho, 42 in Manzini, 25 in Lubombo, and 23 in Shiselweni [6].

In accordance with the Swaziland National ART and Care guidelines of 2014, people living with HIV/ AIDS (PLWHA) with a cluster of differentiation 4 $(\mathrm{CD} 4+)$ count of $\leqslant 350$ cells $/ \mathrm{mm}^{3}$, or who exhibited stage III or IV symptoms according to WHO clinical staging definitions, were eligible for ART initiation. PLWHA with comorbid conditions such as HIVrelated renal failure, hepatitis B virus co-infection, or active tuberculosis (TB) disease were eligible for ART regardless of their CD4+ cell count [1].

National efforts to expand the availability of ART have contributed to lower HIV-related morbidity and mortality. Nevertheless, attrition in PLWHA already on ART is a major challenge undermining ART programme achievements [7]. PLWHA who discontinue treatment are at a high risk of illness and death because of AIDS-related conditions [8].

By 2015, only two studies had addressed factors associated with retention in Swaziland, and neither has been published $[4,9]$. Both studies analysed data derived from smaller sample sizes. For example, in 2010, the Ministry of Health of Swaziland in conjunction with the WHO selected only four healthcare institutions (Mbabane Government Hospital, Hlatikulu Government Hospital, Raleigh Fitkin Memorial Hospital, and Good Shepherd Hospital) for their study; the cohort of 946 PLWHA yielded a loss to follow-up (LTFU) rate of $6.76 \%$ after a 12 -month follow-up period [9]. However, the data on factors associated with LTFU were self-reported, which might have affected LTFU accuracy. According to Mazibuko's estimates [4], attrition rates were 30.9\% and $29 \cdot 1 \%$ for doctor- and nurse-managed cohorts, respectively, for a sample size of 871 participants. Because the general population was not used in either study, their results are not generalizable.

Considering the variability of attrition predictors in sub-Saharan Africa and the shortage of attrition studies in Swaziland, we analysed a large population sample to estimate attrition for the ART programme 12 months after ART initiation and to determine the predictors of attrition in PLWHA treated with ART in Swaziland.

\section{MATERIALS AND METHODS}

\section{Study design and sample}

We conducted a retrospective cohort study using national routinely collected computerized baseline data sourced from the Institute of Health Management. The data were obtained from all medical institutes (both public and private) that provided ART services in Swaziland in 2012. Data were collected from each PLWHA at ART initiation and were aggregated into monthly and quarterly facility reports, which were electronically transmitted to the Institute of Health Management. A total of 16423 persons (aged $\geqslant 20$ years) were newly initiated on ART treatment in 2012. Of these, 2383 were missing data in one or more variables and were therefore excluded from our regression analysis. Consequently, data on 14040 PLWHA were included in our regression analysis.

\section{Measurements}

All participants were followed up until December 2013. Our primary outcome was attrition, which included two mutually exclusive groups: LTFU and mortality. LTFU was defined as a situation whereby a PLWHA has not attended a health facility within 3 months of their most recent scheduled appointment for medication collection, laboratory testing, and/or clinical review and has not been documented as having died. Mortality meant a participant was documented in the facility register as having died. The primary outcome for the survival analysis was retention, which was defined as participants who were alive and in active follow-up at the end of December 2013. Participants who were classified as LTFU during the study but eventually returned before the end of the study were counted as active because their return was a result of defaulter tracing interventions in the programme. 
Information collected at baseline included: demographic and social factors (sex, age, district, the availability of a treatment supporter), clinical factors (TB status, functional status, WHO clinical stage), and facility factors (facility type, ownership). Facility types included primary healthcare facilities (clinics and public health units), secondary healthcare facilities (health centres) and tertiary healthcare facilities (hospitals, referral hospitals). Primary healthcare facilities are the first level of contact between individuals and families within the health system. Secondary healthcare facilities are the middle tier of health system, in which PLWHA from primary healthcare are referred to specialists. Tertiary facilities represents the highest level of the health system, in which specialized care is provided usually by referral from the lower levels.

\section{Statistical analysis}

PLWHA on ART were censored on 31 December 2013. We separated attrition into two mutually exclusive groups (LTFU and mortality) and calculated overall cumulative attrition, LTFU and mortality rates at 3, 6, 9 and 12 months. Rates were calculated by adding the number of participants who discontinued care at each interval and dividing by the total number of participants enrolled in ART in 2012. This was expressed as percentages with $95 \%$ confidence intervals (CIs).

We also performed both univariable and multivariable competing-risk Cox proportional hazard regressions to determine cause-specific predictors of LTFU and mortality after 12 months. A competing-risk Cox regression accounts for the fact that LTFU and mortality are not independent [10]. To maximize the use of all available data in regression, we modelled missing data for each predictor as a separate category, i.e. 'missing'. Only risk factors that were significantly associated with each outcome (LTFU and mortality) were included in the multivariable analysis. We reported hazard ratios with $95 \%$ CIs and corresponding $P$ values. We used the variance inflation factor (VIF) to check for multicollinearity in predictors. No variable had a VIF value $>10$, with 1.28 being the mean VIF.

\section{Ethical standards}

All procedures performed in this study were in accordance with the ethical standards of the Swaziland Scientific and Ethics Committee, which approved the project.

\section{RESULTS}

\section{Characteristics by attrition status}

Table 1 shows that LTFU was higher in females $(6 \cdot 8 \%)$ compared to males $(5 \cdot 5 \%)$, and that mortality was higher in males $(5 \cdot 4 \%$ vs. $3 \cdot 3 \%$ in females). Manzini District had the highest (9.2\%) LTFU compared to other regions, while Shiselweni District had the highest mortality rate $(5 \cdot 7 \%)$. Individuals with advanced HIV/AIDS disease (at WHO stages III and IV) had greater percentages of both LTFU and mortality ( $7 \cdot 6 \%$ and $7 \cdot 7 \%$, respectively) compared to those with mild HV/AIDS disease (WHO stages I and II). PLWHA initiating treatment in private facilities showed the least LTFU $(2 \cdot 2 \%)$, and those who initiated treatment at NGO facilities were least likely to die $(2 \cdot 5 \%)$. The level of missing baseline participant data in this study varied from $2.5 \%$ for TB status, $4 \cdot 4 \%$ for functional status, $7 \cdot 4 \%$ for sex, $9 \cdot 6 \%$ for facility ownership, $14.4 \%$ for facility type to $14.5 \%$ for district.

The overall attrition, LTFU, and mortality rates are presented in Table 2. After a 12-month follow-up period, overall attrition, LTFU, and mortality rates were $10 \cdot 3 \%(95 \%$ CI $10 \cdot 1-10 \cdot 6), 6 \cdot 2 \%(95 \%$ CI $5 \cdot 9$ $6 \cdot 5)$, and $4 \cdot 1 \%(95 \%$ CI $3 \cdot 8-4 \cdot 4)$, respectively. LTFU was low $(0 \cdot 3 \%)$ during the first 3 months, increasing to $4 \%$ at 6 months. Mortality, on the other hand, was $2 \cdot 6 \%$ at 3 months, steadily increasing to $4 \cdot 1 \%$ at 12 months.

\section{Factors associated with attrition}

In the multivariable competing-risk Cox hazards model (Table 3), age group, district, having a treatment supporter at baseline, TB history, WHO clinical stage, facility type, and facility ownership were independent predictors for LTFU. Sex, age group, TB history, functional status, WHO clinical stage, facility type, and facility ownership were independent predictors for mortality.

Compared to young adults, middle-aged and older PLWHA had a lower risk of LTFU, as shown by an adjusted hazard ratio (aHR) of 0.63 (95\% CI $0.5-0 \cdot 7)$ and $0.62(95 \%$ CI $0.5-0 \cdot 8)$, respectively. PLWHA who initiated treatment in facilities in Manzini and Shiselweni districts were at a higher risk of LTFU, with an aHR of $4 \cdot 3(95 \%$ CI $3 \cdot 1-5 \cdot 4)$ and $1.4(95 \%$ CI 1.2-2.0), respectively, compared to those who initiated ART in Hhohho District. The risk of LTFU in PLWHA who had a treatment supporter on ART 
Table 1. Patient and programme characteristics, stratified by primary outcome (retention and attrition)

\begin{tabular}{|c|c|c|c|c|}
\hline \multirow[b]{2}{*}{ Characteristic } & \multirow[b]{2}{*}{ Retention } & \multicolumn{2}{|l|}{ Attrition } & \multirow[b]{2}{*}{ Total } \\
\hline & & LTFU & Mortality & \\
\hline \multicolumn{5}{|l|}{ Demographic and social factors } \\
\hline \multicolumn{5}{|l|}{ Sex } \\
\hline Female & $8975(89 \cdot 9)$ & $677(6 \cdot 8)$ & $326(3 \cdot 3)$ & $9978(60 \cdot 8)$ \\
\hline Male & $5634(89 \cdot 1)$ & $344(5 \cdot 4)$ & $346(5 \cdot 4)$ & $6324(38 \cdot 5)$ \\
\hline Missing & $102(84 \cdot 3)$ & $12(9 \cdot 9)$ & $7(5 \cdot 8)$ & $121(7 \cdot 4)$ \\
\hline \multicolumn{5}{|l|}{ Age, years } \\
\hline $20-34$ & $7730(88 \cdot 9)$ & $662(7 \cdot 6)$ & $298(3 \cdot 4)$ & $8690(52 \cdot 9)$ \\
\hline $35-49$ & $5131(90 \cdot 7)$ & $278(4 \cdot 9)$ & $244(4 \cdot 3)$ & $5653(34 \cdot 4)$ \\
\hline$\geqslant 50$ & $1850(88.9)$ & $93(4 \cdot 5)$ & $137(6 \cdot 5)$ & $2080(12 \cdot 7)$ \\
\hline \multicolumn{5}{|l|}{ District } \\
\hline Hhohho & $2444(90 \cdot 9)$ & $111(4 \cdot 1)$ & $133(4 \cdot 9)$ & $2688(16 \cdot 4)$ \\
\hline Shiselweni & $2408(85 \cdot 8)$ & $239(8 \cdot 5)$ & $160(5 \cdot 7)$ & $2807(17 \cdot 1)$ \\
\hline Manzini & $5171(86 \cdot 8)$ & $547(9 \cdot 2)$ & $241(4)$ & $5959(36 \cdot 3)$ \\
\hline Lubombo & $2324(89 \cdot 9)$ & $124(4 \cdot 8)$ & $138(5 \cdot 3)$ & $2586(15 \cdot 7)$ \\
\hline Missing & $2364(99 \cdot 2)$ & $12(0 \cdot 5)$ & $7(0 \cdot 3)$ & $2383(14 \cdot 5)$ \\
\hline \multicolumn{5}{|l|}{ Have treatment supporter } \\
\hline No & $2152(89 \cdot 4)$ & $170(7 \cdot 1)$ & $85(3 \cdot 5)$ & $2407(14 \cdot 7)$ \\
\hline Yes & $12559(89 \cdot 6)$ & $863(2 \cdot 2)$ & $594(4 \cdot 2)$ & $14016(85 \cdot 3)$ \\
\hline \multicolumn{5}{|l|}{ Clinical factors } \\
\hline \multicolumn{5}{|l|}{ Tuberculosis status } \\
\hline Negative & $14078(90 \cdot 3)$ & $936(6)$ & $578(3 \cdot 7)$ & $15592(94.9)$ \\
\hline Positive & $233(56 \cdot 3)$ & $87(21)$ & $94(22 \cdot 7)$ & $414(2 \cdot 5)$ \\
\hline Missing & $400(95 \cdot 9)$ & $10(2 \cdot 4)$ & $7(1 \cdot 7)$ & $417(2 \cdot 5)$ \\
\hline \multicolumn{5}{|l|}{ Functional status } \\
\hline Bedridden & $112(68 \cdot 7)$ & $11(6 \cdot 7)$ & $40(24 \cdot 5)$ & $163(0 \cdot 9)$ \\
\hline Ambulatory & $1611(89 \cdot 1)$ & $75(4 \cdot 1)$ & $123(6 \cdot 8)$ & 1809 (11) \\
\hline Working & $12272(89 \cdot 4)$ & $935(6 \cdot 8)$ & $516(3 \cdot 8)$ & $13723(83 \cdot 6)$ \\
\hline Missing & $716(98 \cdot 4)$ & $12(1 \cdot 6)$ & - & $728(4 \cdot 4)$ \\
\hline \multicolumn{5}{|l|}{ WHO clinical stages } \\
\hline I and II & $9057(91 \cdot 9)$ & $574(5 \cdot 8)$ & $218(2 \cdot 2)$ & $9849(59 \cdot 9)$ \\
\hline III and IV & $5070(84 \cdot 7)$ & $457(7 \cdot 6)$ & $461(7 \cdot 7)$ & $5988(36 \cdot 5)$ \\
\hline Missing & $584(99 \cdot 7)$ & $2(0 \cdot 3)$ & - & $586(3 \cdot 6)$ \\
\hline \multicolumn{5}{|l|}{ Facility factors } \\
\hline \multicolumn{5}{|l|}{ Facility type } \\
\hline Tertiary healthcare facility & $5822(88 \cdot 1)$ & $471(7 \cdot 1)$ & $312(4 \cdot 7)$ & $6605(40 \cdot 2)$ \\
\hline Secondary healthcare facility & $2868(84 \cdot 4)$ & $316(9 \cdot 3)$ & $216(6 \cdot 4)$ & $3400(20 \cdot 7)$ \\
\hline Primary healthcare facility & $3657(90 \cdot 3)$ & $245(6 \cdot 1)$ & $147(3 \cdot 6)$ & $4049(24 \cdot 7)$ \\
\hline Missing & $2364(99 \cdot 8)$ & $1(0 \cdot 1)$ & $3(0 \cdot 1)$ & $2369(14 \cdot 4)$ \\
\hline \multicolumn{5}{|l|}{ Facility ownership } \\
\hline Mission & $3068(90 \cdot 2)$ & $192(5 \cdot 6)$ & $143(4 \cdot 2)$ & $3403(20 \cdot 7)$ \\
\hline Government & $7204(87)$ & $665(8)$ & $410(4 \cdot 9)$ & $8279(50 \cdot 4)$ \\
\hline Private & $1501(92 \cdot 8)$ & $36(2 \cdot 2)$ & $80(4 \cdot 9)$ & $1617(9 \cdot 8)$ \\
\hline NGO & $1374(88 \cdot 5)$ & $140(9)$ & $39(2 \cdot 5)$ & $1553(9 \cdot 5)$ \\
\hline Missing & $1564(99 \cdot 6)$ & - & $7(0 \cdot 4)$ & $1571(9 \cdot 6)$ \\
\hline
\end{tabular}

LTFU, Lost to follow-up; NGO, non-governmental organization.

initiation was lower (aHR $0 \cdot 5,95 \%$ CI $0 \cdot 4-0 \cdot 7$ ) than in those who did not have a treatment supporter. The hazard of LTFU was higher in PLWHA with a positive TB status (had pulmonary TB at initiation) (aHR 3, 95\% CI 3.1-3.9) than in those with a negative TB status (did not have pulmonary TB at initiation).
PLWHA with advanced HIV/AIDS had a significantly higher risk of LTFU (aHR $1 \cdot 2,95 \%$ CI $1 \cdot 1-$ 1.4) than PLWHA with a mild HIV/AIDS disease. Initiating ART in a secondary healthcare facility was associated with a higher risk of LTFU (aHR $4 \cdot 1,95 \%$ CI $2 \cdot 9-5 \cdot 6$ ) than initiating ART in a primary 
Table 2. Mortality and LTFU distribution by time on antiretroviral treatment ( $A R T)(N=16423)$

\begin{tabular}{llll}
\hline \hline \multirow{2}{*}{ Time on ART } & \multicolumn{2}{l}{ Outcome, $n(\%)[95 \% \mathrm{CI}]$} & \\
\cline { 2 - 4 } & Overall attrition & LTFU & Mortality \\
\hline 3 months & $471(2 \cdot 9)[2 \cdot 6-3 \cdot 2]$ & $42(0 \cdot 3)[0 \cdot 1-0 \cdot 6]$ & $429(2 \cdot 6)[2 \cdot 4-2 \cdot 9]$ \\
6 months & $1231(7 \cdot 2)[6 \cdot 8-7 \cdot 4]$ & $659(4)[3 \cdot 8-4 \cdot 2]$ & $572(3 \cdot 5)[3 \cdot 1-3 \cdot 7]$ \\
9 months & $1547(9 \cdot 4)[9 \cdot 1-9 \cdot 8]$ & $923(5 \cdot 6)[5 \cdot 4-5 \cdot 9]$ & $624(3 \cdot 8)[3 \cdot 4 \cdot 4 \cdot 1]$ \\
12 months & $1705(10 \cdot 3)[10 \cdot 1-10 \cdot 6]$ & $1033(6 \cdot 2)[5 \cdot 9-6 \cdot 5]$ & $672(4 \cdot 1)[3 \cdot 8-4 \cdot 4]$ \\
\hline \hline
\end{tabular}

LTFU, Lost to follow-up.

healthcare facility. Moreover, initiating treatment in a tertiary healthcare facility was associated with a higher risk of LTFU (aHR 1·8, 95\% CI 1·3-2·3) compared to initiating ART in a primary healthcare facility. PLWHA treated in NGO-owned facilities were $1 \cdot 7$-fold more likely to be classified as LTFU than PLWHA treated in government-owned facilities. Compared to government facility, private facility had a lower hazard of LTFU (aHR 0.4, 95\% CI $0 \cdot 3-0 \cdot 6)$.

One major difference between the risks of LTFU and mortality was that sex was a significant predictor of mortality; the risk of mortality for males was 1.4-fold higher than that of females. In addition, in contrast to the risk of LTFU, PLWHA enrolled in privately owned facilities had considerably elevated risks of mortality (aHR 5·2, 95\% CI 3.4-8.2) compared to those enrolled in government-owned facilities.

\section{DISCUSSION}

We calculated the overall attrition rate of ART in Swaziland and separated attrition into LTFU and mortality. Based on our research, this is the first study to use national data incorporating all medical facilities in Swaziland. After a follow-up period of 12 months, we estimated an overall population attrition of $10.3 \%$. This magnitude of attrition is lower than those recorded in other resource-limited treatment programmes, such as in Mozambique and the Democratic Republic of Congo [11, 12]. It is also lower than those reported in the two studies conducted in Swaziland [4, 9]. We attribute the latter difference to the higher accuracy of our data, because it covered the general population and was collected by health professionals for routine clinical management. Thus, our study is the first, most accurate, measure of attrition in Swaziland.
The difference between Swaziland's attrition and rates from other African settings could be caused by the decentralization of ART services that occurred prior to and during the study period. According to the Joint United Nations Programme on HIV/AIDS (UNAIDS), decentralization coupled with various forms of adherence support have proven effective in improving retention in care [7]. In Swaziland, the model of decentralization in HIV care involved point-of-care diagnostics, task shifting to nurse-led primary-care facilities, community support groups, and integration of services [13].

Consistent with our findings, several studies have shown that the risk of mortality is higher in males commencing ART, compared to their female counterparts $[14,15]$. A study of six African countries associated this higher risk to the late initiation of ART by male participants. It is hypothesized that men are more likely to delay access to healthcare because of stigma, male norms that discourage admitting illhealth, and employment responsibilities [16]. A higher background mortality in men in general, regardless of HIV status, could also explain the sex difference in mortality during ART follow-up [15].

Age was a major factor for both mortality and LTFU during the 12-month follow-up period. Similar to findings from previous studies [17, 18], a higher mortality hazard was observed in old-aged participants. One explanation for this association is that CD4 T-cell recovery after starting ART is generally less robust in older PLWHA than in younger participants [19]. In addition, a greater risk of polypharmacy and its attendant adverse consequences (liver and kidney failure) in elderly participants increases their risk of death after initiating ART. Health promotion strategies, therefore, are vital for geriatric participants. For example, routine kidney and liver function tests are essential for this age group to ensure the early detection of drug toxicities and to facilitate early treatment. 
Table 3. Univariable and multivariable competing-risk Cox hazards of factors associated with programme attrition in patients who initiated antiretroviral treatmen in $2012(N=16423)$

\begin{tabular}{|c|c|c|c|c|c|c|c|c|}
\hline \multirow[b]{4}{*}{ Characteristic } & \multicolumn{8}{|l|}{ Outcomes } \\
\hline & \multicolumn{4}{|l|}{ Univariable } & \multicolumn{4}{|l|}{ Multivariable } \\
\hline & \multicolumn{2}{|l|}{ LTFU } & \multicolumn{2}{|l|}{ Mortality } & \multicolumn{2}{|l|}{ LTFU } & \multicolumn{2}{|l|}{ Mortality } \\
\hline & $\mathrm{HR}(95 \% \mathrm{CI})$ & $P$ value & $\operatorname{HR}(95 \% \mathrm{CI})$ & $P$ value & $\mathrm{HR}(95 \% \mathrm{CI})$ & $P$ value & HR $(95 \%$ CI $)$ & $P$ value \\
\hline \multicolumn{9}{|c|}{ Demographic and social factors } \\
\hline \multicolumn{9}{|c|}{ Sex } \\
\hline Female & 1 & & 1 & & 1 & & 1 & \\
\hline Male & $0 \cdot 8(0 \cdot 7-0 \cdot 96)$ & $0 \cdot 01 *$ & $1 \cdot 8(1 \cdot 6-2 \cdot 1)$ & $<0.001^{*}$ & $0 \cdot 9(0 \cdot 8-1 \cdot 1)$ & $0 \cdot 25$ & $1 \cdot 4(1 \cdot 2-1 \cdot 6)$ & $<0 \cdot 001^{*}$ \\
\hline Missing & $0 \cdot 9(0 \cdot 8-1 \cdot 6)$ & $0 \cdot 56$ & $1 \cdot 2(0 \cdot 9-1 \cdot 4)$ & 0.09 & $0.92(0 \cdot 8-1 \cdot 6)$ & $0 \cdot 37$ & $1 \cdot 3(1 \cdot 1-1 \cdot 5)$ & $0 \cdot 07$ \\
\hline \multicolumn{9}{|l|}{ Age, years } \\
\hline $20-34$ & 1 & & 1 & & 1 & & 1 & \\
\hline $35-49$ & $0 \cdot 6(0 \cdot 5-0 \cdot 7)$ & $<0 \cdot 001^{*}$ & $1 \cdot 3(1 \cdot 1-1 \cdot 5)$ & $0 \cdot 006^{*}$ & $0.63(0 \cdot 5-0 \cdot 7)$ & $<0.001^{*}$ & $1 \cdot 1(0 \cdot 9-1 \cdot 3)$ & $0 \cdot 2$ \\
\hline$\geqslant 50$ & $0.58(0 \cdot 5-0 \cdot 7)$ & $<0.001^{*}$ & $1 \cdot 9(1 \cdot 5-2 \cdot 3)$ & $<0.001^{*}$ & $0.62(0 \cdot 5-0 \cdot 8)$ & $<0.001^{*}$ & $1 \cdot 7(1 \cdot 3-2)$ & $<0 \cdot 001 *$ \\
\hline \multicolumn{9}{|l|}{ District } \\
\hline Hhohho & 1 & & 1 & & 1 & & 1 & \\
\hline Shiselweni & $2 \cdot 1(1 \cdot 7-2 \cdot 7)$ & $<0 \cdot 001^{*}$ & $1 \cdot 2(0 \cdot 9-1 \cdot 5)$ & $0 \cdot 21$ & $1 \cdot 4(1 \cdot 2-2)$ & $<0.001^{*}$ & $1 \cdot 3(1-1 \cdot 7)$ & $0 \cdot 08$ \\
\hline Manzini & $2 \cdot 3(1 \cdot 9-2 \cdot 8)$ & $<0 \cdot 001^{*}$ & $0 \cdot 8(0 \cdot 7-1)$ & $0 \cdot 05^{*}$ & $4 \cdot 3(3 \cdot 1-5 \cdot 4)$ & $<0 \cdot 001^{*}$ & $0 \cdot 8(0 \cdot 6-1)$ & $0 \cdot 07$ \\
\hline Lubombo & $1 \cdot 2(0 \cdot 9-1 \cdot 5)$ & 0.96 & $1 \cdot 1(0 \cdot 9-1 \cdot 4)$ & $0 \cdot 52$ & $0 \cdot 98(0 \cdot 7-1 \cdot 3)$ & 0.96 & $1 \cdot 1(0 \cdot 8-1 \cdot 5)$ & $0 \cdot 39$ \\
\hline Missing & $2 \cdot 2(1 \cdot 7-2 \cdot 7)$ & $0 \cdot 74$ & $0 \cdot 9(0 \cdot 6-1 \cdot 2)$ & $0 \cdot 89$ & $3 \cdot 9(3 \cdot 1-5 \cdot 1)$ & $0 \cdot 56$ & $1 \cdot 3(0 \cdot 9-1 \cdot 6)$ & $0 \cdot 21$ \\
\hline \multicolumn{9}{|c|}{ Have treatment supporter } \\
\hline No & 1 & & 1 & & 1 & & - & \\
\hline Yes & $0 \cdot 7(0 \cdot 6-0 \cdot 8)$ & $<0.001^{*}$ & $0 \cdot 9(0 \cdot 8-1 \cdot 2)$ & 0.672 & $0 \cdot 5(0 \cdot 4-0 \cdot 7)$ & $<0 \cdot 001^{*}$ & - & - \\
\hline \multicolumn{9}{|l|}{ Clinical factors } \\
\hline \multicolumn{9}{|c|}{ Tuberculosis status } \\
\hline Negative & 1 & & 1 & & 1 & & 1 & \\
\hline Positive & $3 \cdot 3(2 \cdot 7-4 \cdot 2)$ & $<0.001^{*}$ & $6 \cdot 0(4 \cdot 8-7 \cdot 5)$ & $<0.001^{*}$ & $3(3 \cdot 1-5 \cdot 4)$ & $<0.001^{*}$ & $3 \cdot 7(2 \cdot 9-4 \cdot 7)$ & $<0.001^{*}$ \\
\hline Missing & $1.9(1 \cdot 7-2 \cdot 9)$ & $0 \cdot 45$ & $3 \cdot 4(3 \cdot 1-3 \cdot 8)$ & $0 \cdot 11$ & $2 \cdot 4(2 \cdot 04-3 \cdot 5)$ & $0 \cdot 33$ & $4 \cdot 2(3 \cdot 9-5 \cdot 4)$ & $0 \cdot 24$ \\
\hline \multicolumn{9}{|c|}{ Functional status } \\
\hline Bedridden & 1 & & 1 & & - & & 1 & \\
\hline Ambulatory & $0.9(0 \cdot 5-1 \cdot 7)$ & $0 \cdot 69$ & $0 \cdot 4(0 \cdot 2-0 \cdot 5)$ & $<0.001^{*}$ & - & - & $0.5(0.4-0.7)$ & $<0.001^{*}$ \\
\hline Working & $1 \cdot 1(0 \cdot 6-2)$ & $0 \cdot 76$ & $0 \cdot 1(0 \cdot 09-0 \cdot 2)$ & $<0.001^{*}$ & - & - & $0 \cdot 3(0 \cdot 2-0 \cdot 5)$ & $<0.001^{*}$ \\
\hline Missing & $0 \cdot 8(0 \cdot 6-1 \cdot 5)$ & $0 \cdot 53$ & $0 \cdot 3(0 \cdot 2-0 \cdot 7)$ & $0 \cdot 04^{*}$ & - & - & $0 \cdot 5(0 \cdot 4-1 \cdot 1)$ & 0.07 \\
\hline
\end{tabular}


Table 3 (cont.)

\begin{tabular}{|c|c|c|c|c|c|c|c|c|}
\hline \multirow[b]{4}{*}{ Characteristic } & \multicolumn{8}{|l|}{ Outcomes } \\
\hline & \multicolumn{4}{|l|}{ Univariable } & \multicolumn{4}{|l|}{ Multivariable } \\
\hline & \multicolumn{2}{|l|}{ LTFU } & \multicolumn{2}{|l|}{ Mortality } & \multicolumn{2}{|l|}{ LTFU } & \multicolumn{2}{|l|}{ Mortality } \\
\hline & HR $(95 \%$ CI) & $P$ value & $\mathrm{HR}(95 \% \mathrm{CI})$ & $P$ value & HR $(95 \%$ CI) & $P$ value & $\operatorname{HR}(95 \% \mathrm{CI})$ & $P$ value \\
\hline \multicolumn{9}{|l|}{ WHO clinical stages } \\
\hline I and II & 1 & & 1 & & 1 & & 1 & \\
\hline III and IV & $1 \cdot 3(1 \cdot 1-1 \cdot 5)$ & $0 \cdot 002 *$ & $3 \cdot 7(3 \cdot 5-4 \cdot 5)$ & $<0 \cdot 001^{*}$ & $1 \cdot 2(1 \cdot 1-1 \cdot 4)$ & $0 \cdot 002 *$ & $3 \cdot 2(2 \cdot 6-3 \cdot 8)$ & $<0.001 *$ \\
\hline Missing & $1 \cdot 1(0 \cdot 4-1 \cdot 6)$ & $0 \cdot 49$ & $2 \cdot 4(2 \cdot 1-3 \cdot 5)$ & $0 \cdot 09$ & $1 \cdot 3(0 \cdot 3-1 \cdot 8)$ & $0 \cdot 52$ & $2 \cdot 1(1 \cdot 7-2 \cdot 6)$ & $0 \cdot 12$ \\
\hline \multicolumn{9}{|l|}{ Facility factors } \\
\hline \multicolumn{9}{|l|}{ Facility type } \\
\hline Primary healthcare facility & 1 & & 1 & & 1 & & 1 & \\
\hline Secondary healthcare facility & $1 \cdot 6(1 \cdot 3-1 \cdot 9)$ & $<0 \cdot 001^{*}$ & $1 \cdot 8(1 \cdot 5-2 \cdot 2)$ & $<0 \cdot 001^{*}$ & $4 \cdot 1(2 \cdot 9-5 \cdot 6)$ & $<0 \cdot 001^{*}$ & $2 \cdot 9(1 \cdot 9-4 \cdot 6)$ & $<0 \cdot 001^{*}$ \\
\hline Tertiary healthcare facility & $1 \cdot 2(1 \cdot 04-1 \cdot 4)$ & $0 \cdot 01^{*}$ & $1 \cdot 3(1 \cdot 1-1 \cdot 6)$ & $0 \cdot 004$ & $1 \cdot 8(1 \cdot 3-2 \cdot 3)$ & $<0.001^{*}$ & $2 \cdot 5(1 \cdot 6-3 \cdot 7)$ & $<0 \cdot 001^{*}$ \\
\hline Missing & $1 \cdot 1(0 \cdot 9-1 \cdot 9)$ & $0 \cdot 08$ & $1 \cdot 3(1 \cdot 06-1 \cdot 8)$ & $0 \cdot 09$ & $3 \cdot 3(2 \cdot 6-3 \cdot 9)$ & $0 \cdot 07$ & $1 \cdot 9(0 \cdot 9-3 \cdot 2)$ & $0 \cdot 06$ \\
\hline \multicolumn{9}{|l|}{ Facility ownership } \\
\hline Government & 1 & & 1 & & 1 & & 1 & \\
\hline Private & $0 \cdot 3(0 \cdot 2-0 \cdot 4)$ & $<0.001^{*}$ & $1 \cdot 1(0 \cdot 9-1 \cdot 4)$ & $0 \cdot 39$ & $0 \cdot 4(0 \cdot 3-0 \cdot 6)$ & $<0.001^{*}$ & $5 \cdot 2(3 \cdot 4-8 \cdot 2)$ & $<0.001^{*}$ \\
\hline $\mathrm{NGO}$ & $1 \cdot 3(1 \cdot 04-1 \cdot 5)$ & $0 \cdot 01 *$ & $0.6(0 \cdot 4-0.8)$ & $<0 \cdot 001^{*}$ & $1 \cdot 7(1 \cdot 3-2 \cdot 3)$ & $<0 \cdot 001^{*}$ & $1 \cdot 7(1 \cdot 1-2 \cdot 8)$ & $0 \cdot 04^{*}$ \\
\hline Mission & $0.7(0.6-0.8)$ & $<0.001^{*}$ & $0.9(0 \cdot 7-1 \cdot 1)$ & $0 \cdot 17$ & $0.9(0.6-0.7)$ & $0 \cdot 58$ & $0 \cdot 9(0 \cdot 6-1 \cdot 3)$ & $0 \cdot 59$ \\
\hline Missing & $1 \cdot 1(0 \cdot 7-1 \cdot 7)$ & $0 \cdot 23$ & $0.9(0 \cdot 6-1 \cdot 1)$ & $0 \cdot 19$ & $1 \cdot 4(1 \cdot 1-1 \cdot 8)$ & $0 \cdot 77$ & $1 \cdot 2(09-1 \cdot 9)$ & $0 \cdot 32$ \\
\hline
\end{tabular}

LTFU, Lost to follow-up; HR, hazard ratio; CI, confidence interval; NGO, non-governmental organization

* Statistically significant $P$ value. 
Compared to young adults, both old and middle-aged participants had a lower risk of LTFU. This may be due to their relatively lower mobility [15]. In our analysis, participants who had a treatment supporter on ART initiation were protected from being classified as LTFU. Treatment supporters play a primary role in assisting with PLWHA adherence and retention. This may involve providing emotional support, accompanying the PLWHA for clinic appointments and drug collection, or providing assistance to ensure the participant takes drugs correctly [20]. Because not all PLWHA have relatives and friends available for supporting the continuum of care, an emphasis on community-based support systems can maximize programme retention.

Participants who joined the ART programme with advanced HIV/AIDS had higher risks of LTFU and mortality. Advanced HIV/AIDS is a known risk factor for attrition in PLWHA on ART and is typically a consequence of delaying the start of ART [11, 21]. As in our study, previous studies have found that PLWHA initiating care at PHCFs were more likely to be retained in ART care [22-24]. In the context of Swaziland, this finding may be related to the PHCFs performing higher in-community sensitization through health education, the training of PLWHA, the monitoring of community-based activities, and psychological support compared to secondary and tertiary healthcare facilities. The value of sensitization and other community-based interventions in improving adherence has long been recognized [25].

The highest risk observed in our study was that of dying after initiating treatment at a privately owned facility. Some studies have associated private facilities with suboptimal adherence, lower viral suppression rates, treatment failure, drug resistance, and high mortality [26, 27]. According to Sulzbach et al. [26], a lack of quality HIV services caused by limited training on HIV issues in private sector providers can explain the higher risk of mortality observed in this study.

The following limitations should be considered in interpreting our findings. The retrospective design of the study makes it vulnerable to missing information. Missing data is most likely related to incomplete documentation in facility reports. The problem of missing values underscores the emphasis on attentiveness and complete data collection during treatment initiation in the ART programme in Swaziland. The method we used to deal with missing data may render our results susceptible to bias.

The second limitation is that the true mortality rate may be slightly higher than that reported in this study, because we relied on health professionals to record deaths rather than linking our data to the death registry; the accuracy of our mortality estimates depends on the quality of records provided by these personnel. However, we are confident that estimations from the data collected by health personnel are correct; because the patient tracing programme and patient home visits would have revealed deaths that might not have been otherwise reported by relatives when they occurred.

Our results demonstrate current attrition rates and identify some key factors associated with the risk of attrition for the overall population. Having studied all 110 facilities providing ART services in Swaziland, we can confidently extrapolate our findings to the entire national ART programme. In addition, our findings are likely to yield estimations that are more accurate than previous studies in Swaziland because we analysed secondary data, and the data are not subjected to recall bias. With secondary data, the data collection process is often informed by expertise and professionalism that may not be available to research projects of smaller scale. Our study can form a base of policies, plans, and service delivery strategies for preventing and controlling attrition in Swaziland.

\section{ACKNOWLEDGEMENTS}

This study was supported by the Ministry of Science and Technology, Taiwan (grant no. 102-2314-B-010-015MY3).

\section{DECLARATION OF INTEREST}

None.

\section{REFERENCES}

1. Ministry of Health - Swaziland. Swaziland HIV Incidence Measurement Survey (SHIMS) First Findings Report. 2014 (https://www.k4health.org/sites/default/ files/SHIMS_Report.pdf). Accessed 10 February 2015.

2. United Nations Development Programme (UNDP). Sustaining human progress: reducing vulnerabilities and building resilience. HDR. 2014 (http://www.unaids. org/sites/default/files/en/dataanalysis/knowyourresponse/ countryprogressreports/2012countries/ce_SZ_Narrative_ Report[1].pdf). Accessed 4 January 2015.

3. Dlamini PS, et al. HIV stigma and missed medications in HIV-positive people in five African countries. AIDS patient care and STDs 2009; 23: 377-387.

4. Mazibuko S. Decentralization of antiretroviral treatment in Swaziland: outcome of nurse initiated versus doctor initiated treatment: University of Pretoria, 2006. 
5. van Schalkwyk C, et al. Outcomes and impact of HIV prevention, ART and TB programs in Swazilandearly evidence from public health triangulation. PLoS ONE 2013; 8: e69437.

6. Ministry of Health-Swaziland. Round of the HIV Sentinel Serosurveillance Survey. 2011 (http://s3. amazonaws.com/zanran_storage/www.fhi.org/Content Pages/2304502.pdf). Accessed September 2014.

7. UNAIDS. Swaziland country report on monitoring the political declaration on HIV and AIDS. 2012.

8. Miller CM, et al. Why are antiretroviral treatment patients lost to follow-up? A qualitative study from South Africa. Tropical Medicine \& International Health 2010; 15: 48-54.

9. Ministry of Health-Swaziland, World Health Organization. Assessment of loss-to-follow-up and associated factors among ART clients in Swaziland. 2010 (http://www. stopaidsnow.org/sites/stopaidsnow.org/files/filemanager/ TasP_M-Health_MaxART-LTFU_Report_2010_Dec. pdf). Accessed August 2014.

10. Fine JP, Gray RJ. A proportional hazards model for the subdistribution of a competing risk. Journal of the American Statistical Association 1999; 94: 496-509.

11. Molfino L, et al. High attrition among HIV-infected patients with advanced disease treated in an intermediary referral center in Maputo, Mozambique. Global Health Action 2013; 7: 23758.

12. Ditekemena $\mathbf{J}$, et al. Antiretroviral treatment program retention among HIV-infected children in the Democratic Republic of Congo. PLoS ONE 2014; 9: e113877.

13. Turashvili M, et al. Decentralisation of HIVITB care in Shiselweni region of Swaziland: making a difference. 2014. Vienna Evaluation Unit (http://fieldresearch.msf. org/msf/bitstream/10144/325599/1/49_Swaziland $\% 20$ HIV_ TB_decentralization_combined\%20report_July\%202014. pdf). Accesed October 2014.

14. Braitstein P, et al. Mortality of HIV-1-infected patients in the first year of antiretroviral therapy: comparison between low-income and high-income countries. Lancet 2006; 367: 817-824.

15. Auld AF, et al. Temporal trends in mortality and loss to follow-up among children enrolled in Côte d'Ivoire's national antiretroviral therapy Programme. Pediatric Infectious Disease Journal 2014; 33: 1134-1140.

16. Centers for Disease Control and Prevention. Differences between HIV-infected men and women in antiretroviral therapy outcomes-six African countries, 2004-2012. Morbidity and Mortality Weekly Report 2013; 62: 945.

17. Boulle A, et al. Seven-year experience of a primary care antiretroviral treatment programme in Khayelitsha, South Africa. AIDS 2010; 24: 563-72.

18. Nash D, et al. Long-term immunologic response to antiretroviral therapy in low-income countries: collaborative analysis of prospective studies: The Antiretroviral Therapy in Lower Income Countries (ART-LINC) Collaboration of the International epidemiological Databases to Evaluate AIDS. AIDS (London, England) 2008; 22: 2291.

19. Scholten F, et al. Health and functional status among older people with HIV/AIDS in Uganda. BMC Public Health 2011; 11: 1.

20. World Health Organization. Guidelines on co-trimoxazile prophylaxis for HIV-Related infections among children, adolescents and adults. 2006. (http://www.who.int/hiv/ pub/guidelines/ctxguidelines.pdf). Accessed January 2015.

21. Koole O, et al. Retention in a NGO supported antiretroviral program in the Democratic Republic of Congo. PLoS ONE 2012; 7: e40971.

22. Mutasa-Apollo T, et al. Patient retention, clinical outcomes and attrition-associated factors of HIV-infected patients enrolled in Zimbabwe's National Antiretroviral Therapy Programme, 2007-2010. PLoS ONE 2014; 9: e86305.

23. Decroo T, et al. Lessons learned during down referral of antiretroviral treatment in Tete, Mozambique. Journal of the International AIDS Society 2009; 12: 6.

24. Fatti G, Grimwood A, Bock P. Better antiretroviral therapy outcomes at primary healthcare facilities: an evaluation of three tiers of ART services in four South African provinces. PLoS ONE 2010; 5: e12888.

25. Rueda S, et al. Patient support and education for promoting adherence to highly active antiretroviral therapy for HIV/AIDS. Cochrane Database of Systematic Reviews 2006; 3 (3).

26. Sulzbach S, Wang W, Ohanlon B. Assessing the role of the private health sector in HIV/AIDS service delivery in Ethiopia, 2009.

27. Ekstrand ML, et al. Suboptimal adherence associated with virological failure and resistance mutations to first-line highly active antiretroviral therapy (HAART) in Bangalore, India. International Health 2011; 3: 27-34. 